\title{
Diferença de classe no SUS: discursos favoráveis em audiência pública no STF em 2014
}

Class differences in SUS: favourable speeches in public hearing at the Supreme Court in 2014

Diferencia de clase en el SUS: discursos favorables en la audiencia pública en el STF en 2014

\section{Mayara Mota Martins ${ }^{1}$}

Resumo: Diante do pedido do Conselho Regional de Medicina do Estado do Rio Grande do Sul, que demanda a instituição da chamada 'Diferença de classe no SUS', o Supremo Tribunal Federal convocou audiência pública para a oitiva de especialistas e pessoas com experiência na área da saúde a fim de subsidiar a decisão desta corte. A diferença de classe consiste na melhoria de acomodação recebida pelo usuário no caso da sua internação, e a contratação do profissional médico de sua preferência mediante o pagamento da respectiva diferença. Este trabalho tem como objetivo analisar os argumentos favoráveis à diferença de classe no SUS proferidos na audiência pública 'Internação Hospitalar com diferença de classe no SUS' realizada no dia 26 de maio de 2014 no STF, e fazer uma reflexão sobre de que forma essa medida poderia impactar o SUS frente aos seus princípios e diretrizes, por meio da análise de discurso. Verificou-se que a diferença de classe se mostra incompatível com o SUS, já que este tem como diretrizes a igualdade e universalidade do atendimento sem privilégios de qualquer espécie. Ademais, a instituição da diferença de classe no SUS não somente fere a legislação brasileira, como representa um retrocesso no que tange os direitos sociais. Com esse entendimento a Suprema Corte aboliu a diferença de classe julgando favoravelmente ao SUS.

Palavras-chaves: Diferença de Classe, Decisão Judicial, Hospitalização, Sistema Único de Saúde

Abstract: On the request of the Regional Council of Medicine of Rio Grande do Sul State, which requires the establishment of so-called 'class difference in SUS', the Supreme Court has convened a public hearing for the hearing of experts and people with experience in the field of health in order to support the decision of this Court. The class difference is the improvement of accommodation received by the user in the event of his/her hospitalization, and the hiring of medical professional of his/her choice upon payment of the respective difference. This paper aims to examine the arguments in favour of class difference in SUS delivered in open court 'Hospitalization with class difference in SUS' held on May 26 ${ }^{\text {th }}, 2014$ in the Supreme Court, and to reflect on how this measure could impact the SUS according to its principles and guidelines, by means of speech analysis. It was found that the class difference is incompatible with SUS, since it has as guidelines equality and universality of care without privileges of any kind. Furthermore, the institution of class difference in SUS not only hurts Brazilian legislation, as it represents a step backwards regarding social

\footnotetext{
${ }^{1}$ Bacharel em Saúde Coletiva pela Universidade de Brasília (UnB), Brasília/DF. E-mail: mayara_777@hotmail.com.
} 
rights. With this understanding the Supreme Court abolished the class difference judging favorably to SUS

Keywords: Class Difference, Public hearing, Hospitalization, Unified Health System

Resumen: La petición del Consejo Regional de Medicina de Río Grande do Sul, que requiere el establecimiento de la llamada "diferencia de clases en el SUS ', la Suprema Corte convocó a una audiencia pública para la audiencia de expertos y personas con experiencia en salud con el fin de apoyar la decisión de este tribunal. La diferencia de clases es la mejora de alojamientos recibida por el usuario en caso de su hospitalización, y la contratación de profesional médico de su elección mediante el pago de la respectiva diferencia. Este artículo tiene como objetivo examinar los argumentos a favor de la diferencia de clases en el SUS entregado en audiencia pública 'Hospitalización con diferencia de clases en el SUS, celebrada el 26 de mayo de 2014 en el Tribunal Supremo, y para reflexionar sobre cómo esta medida podría afectar el frente NHS de sus principios y directrices, por medio del análisis del discurso. Se encontró que la diferencia de clases es incompatible con el SUS, ya que tiene como directrices igualdad y universalidad del servicio sin privilegios de ningún tipo. Por otra parte, la institución de la diferencia de clases en el NHS no sólo perjudica a la legislación brasileña, ya que representa un retroceso en materia de derechos sociales. Con este entendimiento de la Corte Suprema abolió la diferencia de clase a juzgar favorablemente a

Palabras-Ilave: Diferencia de Clase, Audiencia pública, Hospitalización, Sistema Único de la Salud

\section{Introdução}

A audiência pública, objeto de análise deste trabalho, foi convocada pelo Supremo Tribunal Federal (STF) com vistas a possibilitar a esta corte melhor entendimento a respeito do que convencionou-se chamar de 'Diferença de classe no SUS'. A audiência diz respeito a recurso extraordinário com repercussão geral reconhecida interposto pelo Conselho Regional de Medicina do Estado do Rio Grande do Sul (CREMERS) contra decisão do Tribunal Regional Federal da 4a Região (TRF-4). O TRF-4 considerou improcedente ação civil pública ajuizada pelo CREMERS que tinha como objetivo permitir a prática da diferença de classe no Sistema Único de Saúde (SUS).

A diferença de classe, como pleiteada pelo CREMERS, consiste na melhoria de acomodação recebida pelo usuário no caso da sua internação, e a contratação do profissional médico de sua preferência mediante o pagamento da respectiva diferença dentro do Sistema Único de Saúde, que tem como pilares constitucionais a igualdade e universalidade.

A audiência pública é um instrumento que o Supremo pode utilizar para ouvir o depoimento de pessoas com experiência e autoridade em determinada matéria, como 
especialistas e representantes do poder público, para obtenção de informações acerca da questão, de modo a subsidiar sua decisão, sempre que entender necessário o esclarecimento de questões ou circunstâncias de fato, com repercussão geral e de interesse público relevante, debatidas no âmbito do Tribunal (1).

A iniciativa do Tribunal de realizar essa audiência pública mostra como as questões da área da saúde estão cada vez mais próximas do Poder Judiciário. Isso se torna ainda mais evidente no caso do STF por este ser o guardião da Constituição e o responsável por proteger os direitos garantidos nela, sendo a saúde um deles.

O STF é a suprema corte brasileira e suas decisões são tidas como referência para outros tribunais. Logo, a decisão sobre a diferença de classe pode influenciar as demais instâncias do poder judiciário no julgamento de demandas semelhantes, e abrir a possibilidade, ou não, da instituição dessa diferença de acesso dentro do SUS. Diante da complexidade do tema, da relevância jurídica e social, e dos interesses diversos envolvidos, o STF entendeu por bem realizar uma audiência pública.

É preciso refletir sobre como a diferença de classe seria possível no SUS, se existe essa possibilidade legal e que impactos administrativos e sociais ela poderia trazer. Foram essas questões que se buscou esclarecer durante a audiência pública.

Este trabalho tem como objetivo analisar os argumentos favoráveis à instituição da diferença de classe dentro do SUS proferidos na audiência pública, e fazer uma reflexão sobre de que forma essa medida poderia impactar o SUS frente aos seus princípios e diretrizes, caso seja acatada pelo Poder Judiciário.

\section{Metodologia}

Foi realizada pesquisa qualitativa analítica utilizando a análise de discurso. Foi feita uma análise dos discursos favoráveis à diferença de classe proferidos na audiência pública 'Internação Hospitalar com diferença de classe no SUS' realizada no dia 26 de maio de 2014, no Supremo Tribunal Federal. De 15 discursos proferidos, 3 foram favoráveis à diferença de classe, e esses que serão objeto de análise deste trabalho. $O$ material analisado foi o texto da transcrição da audiência, disponível no site do próprio tribunal (http://www.stf.jus.br). 
A análise de discurso é uma interpretação, que não considera somente o conteúdo do texto em si, mas trabalha principalmente com o sentido que o sujeito manifesta em seu discurso. Essa análise pressupõe a relação entre a posição discursiva do sujeito e fatores sociais, históricos e ideológicos. $\mathrm{Na}$ análise de discurso a linguagem vai além do texto trazendo outros sentidos pré-construídos a partir da memória coletiva constituída socialmente (2).

A abordagem qualitativa busca entender as representações e os significados de aspectos não quantificáveis da realidade. Procura identificar, compreender e interpretar esses fenômenos como explica Turato (3): "[O método qualitativo] tem o fim comum de criar um modelo de entendimento profundo de ligações entre elementos, isto é, de falar de uma ordem que é invisível ao olhar comum".

Gerhardt e Silveira (4) explicam as principais características do método qualitativo:

Objetivação do fenômeno; hierarquização das ações de descrever, compreender, explicar, precisão das relações entre o global e o local em determinado fenômeno; observância das diferenças entre o mundo social e o mundo natural; respeito ao caráter interativo entre os objetivos buscados pelos investigadores, suas orientações teóricas e seus dados empíricos.

Para analisar os discursos selecionados, foram lidas, integralmente, cada uma das transcrições das falas identificadas como favoráveis à diferença de classe. A partir de cada fala, foram extraídos seus argumentos principais entendidos como expressões-chave, e a partir das expressões-chave foram identificadas suas ideias centrais.

Expressões-chave, segundo Lefevre e Lefevre (5), são as expressões que revelam a essência dos argumentos trazidos pelos autores das falas da audiência pública. Essas expressões sintetizam os argumentos sustentados pelos atores. E as ideais centrais, por sua vez, de acordo com os mesmos autores, são as expressões linguísticas que descrevem, da forma mais sintética e precisa possível, o sentido de cada expressão-chave (ou conjunto homogêneo de expressões-chave). Assim, a ideia central é uma descrição sintética do sentido dos argumentos encontrados.

As ideias centrais foram sintetizadas em quatro enunciados principais, que foram objeto de análise. Utilizou-se como material de apoio os vídeos da audiência pública, legislação correlata e bibliografia relacionada ao tema. Por fim, se fez uma análise da possível repercussão da decisão do STF no contexto no Sistema Único de Saúde e as suas implicações sociais. 


\section{Resultados e discussão}

\section{Contexto da audiência}

O Supremo Tribunal Federal convocou, para esta audiência pública, especialistas e profissionais que representaram as seguintes instituições: Ministério Público da União, Conselho Regional de Medicina do Estado do Rio Grande do Sul, Agência Nacional de Saúde Suplementar, Procuradoria do Estado do Rio Grande do Sul, Confederação Nacional de Saúde, Conselho Nacional de Saúde, Conselho Estadual de Saúde do Estado do Rio Grande do Sul, Hospital Sírio Libanês, Conselho Nacional de Secretários de Saúde, Conselho Nacional de Secretários Municipais de Saúde, Procuradoria do Município de Canela, Confederação das Santas Casas de Misericórdia, Tribunal de Contas da União, Associação Brasileira de Saúde Coletiva e Ministério da Saúde.

Cada expositor teve 15 minutos para discutir suas ideias de acordo com seu posicionamento sobre a demanda. Foram analisados somente os discursos favoráveis à diferença de classe, três discursos de um total de quinze, são eles: o discurso do Conselho Regional de Medicina do Estado do Rio Grande do Sul representado pelo médico Cláudio Balduino Souto Franzen; o discurso da Confederação Nacional de Saúde (CNS) representada por Alexandre Venzon Zanetti; e o discurso da Confederação das Santas Casas de Misericórdia (CMB), representada por Júlio Dornelles de Matos.

No quadro 1, encontra-se a relação de expositor e as ideias centrais extraídas a partir da leitura dos discursos e da identificação de suas expressões-chave. 
Quadro 1 - Expositores e suas respectivas ideias centrais

\begin{tabular}{|c|l|}
\hline Expositor & \multicolumn{1}{|c|}{ Ideias centrais } \\
\hline Cláudio Balduino Souto Franzen. (CREMERS) & $\begin{array}{l}\text { A diferença de classe é um direito do cidadão de } \\
\text { escolher o melhor tratamento para si; } \\
\text { A autonomia do médico é fundamental no exercício } \\
\text { da profissão; } \\
\text { A modalidade traria maior aporte de recursos para o } \\
\text { SUS; }\end{array}$ \\
\hline Alexandre Venzon Zanetti. & $\begin{array}{l}\text { A diferença de classe está relacionada à } \\
\text { democracia; } \\
\text { A modalidade não é vedada pela legislação } \\
\text { brasileira, e pode ser instituída de forma regrada e } \\
\text { ordenada; }\end{array}$ \\
\hline Júlio Dornelles de Matos. & $\begin{array}{l}\text { A modalidade não é vedada pela legislação } \\
\text { brasileira, e pode ser instituída de forma regrada e } \\
\text { ordenada; } \\
\text { A modalidade traria maior aporte de recursos para o } \\
\text { SUS; } \\
\text { A diferença de classe é um direito do cidadão de } \\
\text { escolher o melhor tratamento para si; }\end{array}$ \\
\hline
\end{tabular}

A partir disso, as ideias similares foram agrupadas e sintetizadas em 4 enunciados principais que serão objeto de análise (Quadro 2):

Quadro 1 - Principais enunciados

\begin{tabular}{|c|l|}
\hline A & $\begin{array}{l}\text { A diferença de classe é um direito do cidadão de escolher o melhor } \\
\text { tratamento para si. }\end{array}$ \\
\hline B & A modalidade traria maior aporte de recursos para o SUS. \\
\hline C & $\begin{array}{l}\text { A modalidade não é vedada pela legislação brasileira, e pode ser adotada } \\
\text { de forma regrada e ordenada. }\end{array}$ \\
\hline D & A autonomia do médico é fundamental no exercício da profissão. \\
\hline
\end{tabular}


As ideias foram analisadas levando em consideração o contexto social da saúde no qual se insere o debate da diferença de classe, e instituição a qual o autor do discurso está representando. Foram utilizadas legislação e bibliografia correlatas a fim de dar maior fidedignidade e embasamento teórico a esse processo. A seguir, apresentaremos as ideias delineadas pelos expositores, bem como a discussão de cada uma delas, com base nas citadas legislações e bibliografias.

\section{Categorias e respectivas análises}

\section{a) A diferença de classe é um direito do cidadão de escolher o melhor tratamento para si.}

A ideia da diferença de classe no SUS é apresentada como um direito de cidadania do usuário dos serviços de saúde: "discute-se a opção por um quarto diferenciado, a partir de um direito absolutamente prescrito e negociável de um acesso universal, integral e gratuito ao SUS, internação e enfermarias”.

A adoção dessa modalidade seria justificada pelos diversos problemas que o SUS enfrenta hoje como as superlotações nas emergências hospitalares, a carência de profissionais e de equipamentos e insuficiência de leitos, e as condições de trabalho dos médicos. Afirma-se: 'O SUS real não é o SUS idealizado'.

A diferença de classe seria uma forma de fuga da formação de grandes filas, da demora nos atendimentos e da falta de resolutividade dos serviços ofertados pela rede pública. Para ilustrar essa situação, um dos expositores, ao trazer uma apresentação de slides, dá um exemplo: "aqui nós estamos vendo um cidadão, nu, sentado numa lixeira, fazendo as suas necessidades, dentro de uma enfermaria. Lá no canto se vê uma paciente do sexo feminino no mesmo ambiente. Isto é cidadania?".

Nesse contexto, a nova modalidade possibilitaria melhores acomodações dentro do Sistema Único de Saúde, com o pagamento da diferença de custos e consequentemente daria condições mais dignas de tratamento, diferente do caso do cidadão que utilizou como exemplo. Para reforçar esse pensamento o sujeito do discurso destaca também o processo de desativação de leitos nos últimos anos e as taxas de ocupação das emergências, que se apresentaram maiores do que a capacidade máxima. 
Esses problemas enfrentados pelo SUS estariam, dessa forma, ameaçando a dignidade de seus usuários: "enfatizo que o que se pretende é priorizar a dignidade do brasileiro, oferecendo acesso a políticas públicas, efetivamente de qualidade”.

A diferença de classe entendida como um direito de cidadania também consiste em escolher o médico de sua preferência para lhe prestar atendimento, como ressalta 0 sujeito: "direito de o paciente escolher o médico de sua confiança para ser hospitalizado".

Nesse ponto do discurso a não admissão da diferença de classe estaria ferindo um direito do usuário: "proibir que o cidadão que tenha condições de se internar numa acomodação um pouco melhor do que aquelas que eu mostrei ali não possa, isto é tirar o direito de cidadania. Obrigar o paciente a se sujeitar a ser atendido pelo médico com o qual não tem relação de confiança é uma agressão à cidadania".

A escolha de ter uma acomodação melhor dentro do sistema é evidenciada como um direito, ainda, no seguinte trecho: "se, por uma necessidade ou por uma possibilidade, eu possa obter uma localização melhor, mais adequada, mais ajustada a minha necessidade, mais confortável para minha família, por que, para isso, por esta condição, eu tenho de abrir mão do meu direito constitucional, que é a minha AlH?”. Ainda nessa linha de pensamento o expositor ressalta o texto constitucional que define a saúde como direito de todos e dever do Estado, devendo ser prestada de forma igualitária.

Essa primeira ideia, como foi visto, defende a diferença de classe como um direito inerente à condição de cidadania. O que é, de fato, direito do cidadão, positivado na Constituição Federal de 1988, é o direito à saúde, a ser garantido pelo Estado através do Sistema Único de Saúde (SUS).

Quando se fala nos serviços prestados pelo SUS é preciso entender o caráter social que o sistema assume desde a época em que era apenas idealizado. Numa sociedade em que a saúde era espécie de concessão do Estado, e somente a trabalhadores formais, o SUS representa um mecanismo de ampliação da cidadania e inclusão social na medida em que tem como princípios a universalidade de acesso aos serviços e igualdade da assistência.

Levando em consideração essas características do sistema, parece controverso a instituição de uma modalidade de atendimento dentro do SUS que é pautada justamente na questão da diferença de renda ou capacidade financeira. Nesse debate, surge o argumento de que o judiciário brasileiro já deferiu pedidos que demandaram tratamentos e 
acomodações diferenciadas. Mas, é importante destacar sob que circunstâncias esses pedidos foram acatados.

Esses pedidos de assistência diferenciada são feitos com base na necessidade de saúde do paciente, que pode ser uma doença rara que requeira acomodação ou medicamento diferenciado, por exemplo. Essa diferença, feita com base na necessidade médica, se torna imprescindível para a qualidade de vida do paciente e até para o aumento de sua sobrevida. O mesmo não acontece na diferença de classe, porque essa propõe tratamento diferenciado com base no conforto.

É importante falar também sobre equidade. Genericamente, a equidade tem sido definida como 'tratar igualmente os iguais e desigualmente os desiguais'. Partindo disso, poder-se-ia dizer então que a diferença de classe encontra suporte nessa definição? Afinal permitiria tratar desigualmente (com acomodações melhores) os desiguais (pessoas com melhores condições financeiras).

Mas, a questão não é tão simples quando se fala, novamente das características do sistema de saúde brasileiro. A equidade dentro do SUS assume uma forma mais complexa. Não há como falar em equidade sem falar das necessidades sociais de saúde, e são essas necessidades em saúde que dão origem às diferenças: "nem toda diferença na situação de saúde das populações pode ser considerada iniquidade. Mas toda diferença ou desigualdade redutível, vinculada a condições heterogêneas de vida, constitui iniquidade" (6).

Assim, nem toda diferença é necessariamente ruim. Whitehead (7) define iniquidade como diferenças consideradas desnecessárias e evitáveis, mas também injustas e indesejáveis e que, para descrever determinada situação como injusta, a causa deve ser julgada injusta dentro do contexto social.

"Assim, nem toda desigualdade constitui iniquidade no sentido de injustiça. A iniquidade pode ser considerada como uma 'desigualdade injusta', que poderia ser evitada, daí sua importância para os tomadores de decisão (8)".

Analisando sob esse ponto de vista a diferença de classe, diferença essa pautada pelo poder econômico, seria sim uma diferença desnecessária, evitável, injusta e indesejável. A sociedade brasileira ainda é marcada pela desigualdade em várias esferas, e especialmente na saúde, a situação não é diferente: 
Desigualdades sociais nas condições de saúde e no acesso e na utilização de serviços de saúde expressam oportunidades diferenciadas em função da posição social do indivíduo e caracterizam situações de injustiça social, ou seja, iniquidades (9).

A instituição da modalidade da diferença de classe só contribuiria ainda mais para o avanço das iniquidades e produziria um processo de estratificação dos usuários, realidade vivenciada pelo Brasil no período anterior ao SUS. Reforçaria a segregação social que ainda existe na saúde e fortaleceria a discriminação. Então como adotar esse tipo de tratamento num sistema que se propõe a ser universal e igualitário?

É importante destacar o papel do sistema de saúde como um dos determinantes das desigualdades sociais nas condições de saúde e sua responsabilidade na redução delas. Como citado no Relatório Final da Comissão Nacional sobre Determinantes Sociais da Saúde (CNDSS), em 2008, as desigualdades sociais no acesso e na utilização de serviços de saúde estão, em grande medida, relacionadas com a estrutura e funcionamento dos sistemas de saúde, o que faz com que tais desigualdades sejam bastante permeáveis às políticas setoriais (10). Para Travassos e De Castro (9) a ação do sistema pode contribuir para reduzir essas desigualdades.

Falar de diferença de classe é falar de acomodação diferenciada, de profissional da preferência do paciente, mas é, também, falar de acesso. O acesso a saúde no Brasil é influenciado por fatores geográficos, informacionais, financeiros, culturais, relacionado a escolaridade, entre outros. Acesso diz respeito à capacidade dos indivíduos de utilizarem os serviços de saúde.

As barreiras financeiras que permeiam o sistema brasileiro fazem com que os mais pobres utilizem menos os serviços do que as pessoas mais ricas, contribuindo diretamente para o aumento das desigualdades sociais (9). A diferença de classe implicaria em mais uma barreira financeira ao instituir o copagamento:

A incorporação de medidas como copagamento, no qual as pessoas pagam uma parcela do valor do cuidado recebido, tem efeito negativo sobre a equidade no acesso. Em contrapartida, políticas de universalização do acesso voltam-se para reduzir as barreiras financeiras (9).

Também é importante fazer uma reflexão sobre qual o sentido de cidadania abordado nessa discussão. O sujeito do discurso fala de uma cidadania regulada pelo poder aquisitivo. Já a ideia de cidadania que deu as bases para construção do SUS está ligada à participação social, democracia e igualdade. Sob essa perspectiva, entende-se, 
então, que a diferença de classe não é um direito do cidadão. $O$ acesso universal e igualitário, sim, o é.

\section{b) A modalidade traria maior aporte de recursos para o SUS.}

Outro argumento usado foi a possibilidade de a diferença de classe trazer mais recursos para o SUS. Para embasar essa afirmação, o expositor traz alguns dados da Santa Casa de Porto Alegre que mostra a relação do custo efetivo dos procedimentos realizados pela Santa Casa e o valor pago a ela pelo SUS: "vejam o quanto paga o SUS e quanto custa para a Santa Casa prestar assistência: insuficiência respiratória aguda, o custo é de $R \$ 4.517,85$, isto é contabilidade, isto é real, e a tabela paga $R \$ 480,87$ " e daí por diante.

Esse déficit seria prejudicial tanto para o SUS, que já sofre com o subfinanciamento, quanto para as Santas Casas: "existe a possibilidade de agregar valor à internação que é realizada com a $\mathrm{AlH}$, a que todo cidadão tem direito. $\mathrm{E}$ com isso nós aumentarmos o financiamento do sistema público e privado de saúde". Aqui, ele destaca o fechamento de hospitais no Rio Grande do Sul e a 'quebra' de Santas Casas no estado: 'foram fechados 167 hospitais neste período de vinte anos, em que o SUS foi instituído”. Também seria uma oportunidade de acabar com a 'onda de fechamento de leitos'.

Então, o copagamento seria uma alternativa para diminuir esses prejuízos: "com esta modalidade que nós estamos propondo, teria um aporte de recursos que certamente seria utilizado para todos os cidadãos que procuram a Santa Casa”. Como consequência, os usuários do sistema público seriam beneficiados: "a participação do usuário no sistema permitirá aporte de recursos, que poderá melhorar a condição de atendimento nas enfermarias".

Em suma, acredita-se na melhoria na contraprestação do serviço e na possibilidade de investimentos e adequações físicas.

O argumento de que a diferença de classe traria mais recursos para o SUS é sustentado nos problemas financeiros das Santas Casas e outras instituições filantrópicas que não recebem do SUS o valor real devido pelos procedimentos realizados, e também é apresentada como uma alternativa para os problemas do subfinanciamento. 
Porém, analisando em termos práticos essa seria uma tarefa difícil de ser concretizada. É preciso pensar em como a regulação de leitos seria afetada, já que o SUS tem dinâmica própria na realização dessa atividade. No caso da diferença de classe, a quem caberia estabelecer critérios de melhor ou pior acomodação? Com base em quais parâmetros? Como seria possível regular uma relação que se dá entre profissional e paciente, ou entre hospital e paciente? O valor seria pago diretamente ao profissional ou ao hospital? Como isso se daria com relação aos leitos de UTI, que já estão em números insuficientes?

É complicado inserir todo esse cenário de lógica de mercado num sistema de saúde como o brasileiro, ainda mais pelo fato da assistência à saúde ser livre à iniciativa privada. Se o cidadão deseja um quarto diferenciado, com melhores condições de hotelaria, com profissional de sua preferência, e entende que, pelo seu poder aquisitivo isso lhe é devido, por que então não buscar atendimento diretamente no setor privado?

O problema do financiamento do SUS é importante sim, e deve ser discutido, porém nas instâncias e com os atores apropriados. O subfinanciamento não pode servir de justificativa para se estabelecer um sistema que resulta na quebra da isonomia e no tratamento com base em privilégios, aspectos completamente antagônicos ao que o SUS representa hoje.

Portanto, parece que nesse contexto o SUS seria o menos beneficiado, inclusive em termos financeiros. Não é possível inferir que esses recursos provenientes do copagamento iriam ser revertidos para o sistema público de alguma forma.

Por fim, é preciso pensar como ficaria a participação e o controle social no contexto da diferença de classe. Se a própria atividade de regulação ficaria mais difícil de ser realizada, o controle da sociedade sobre as ações oferecidas pelo SUS seria muito prejudicado. Seria mais uma barreira dentro de tantas que a participação popular já enfrenta.

\section{c) A modalidade não é vedada pela legislação brasileira, e pode ser adotada de forma regrada e ordenada.}

De acordo com os expositores a diferença de classe não é proibida pela legislação brasileira. Eles não enxergam na Constituição ou em lei ordinária nenhum enunciado que 
vede a diferença de classe: "a Constituição não veda, e não há nenhuma lei que diga que não há essa possibilidade".

Para eles, as alegações contra a diferença de classe, tida como um direito, não teriam base sólida: "os fundamentos da medida restritiva que proíbe a diferença de classe não têm peso suficiente para restringir um direito fundamental". A não admissão desse tipo diferenciado de tratamento contribuiria para a piora dos serviços da rede pública: "a rede não pode ser sucateada para defender tese ideológica, desprovida de comprovação prática”.

Para fundamentar esse ponto, afirma-se que a CF/88 determinou que o acesso à saúde deve ser universal e igualitário e que, como coloca o artigo 5ำ, todos são iguais perante a lei. Então, a modalidade "não é vedada nem pela Constituição, quando diz que o acesso é universal é igualitário, portanto é igual a mim também".

Eles também defendem a ideia de que a diferença de classe pode ser admitida sem que haja uma modificação significativa do sistema de saúde: "não me parece haver a necessidade de uma mudança tão radical por adotarmos o regime constitucional tal qual ele está escrito". Em outro momento afirma: "não vejo por que modificar todo o sistema de ingresso no SUS para dar ao cidadão a possibilidade de, em caso de necessidade ou querer, ter uma acomodação melhor".

Nessa linha de pensamento, de que poucas mudanças seriam feitas no sistema para tornar a diferença de classe possível, afirma-se: "se isso for feito de uma forma regrada, de uma forma ordenada, isso sim pode, talvez, ajudar a salvar a saúde deste país".

Então a modalidade seria possível se instituída com base na razoabilidade e proporcionalidade:

Somos favoráveis à diferença de classe, mediante a adoção do princípio da proporcionalidade; que, conceitualmente, a gente pode tratar que os princípios que prescrevem a proteção, tanto do interesse público, quanto do interesse privado, deverão ser ponderados por meio do princípio da proporcionalidade, afastando-se dogmas de sobreposições de um ante o outro.

Voltando a Constituição, um dos objetivos da República é a construção de uma sociedade livre justa e solidária. Assim justifica-se:

Livre, na medida em que se garanta a autonomia do cidadão de fazer as suas escolhas e contratar da forma que melhor lhe aprouver. Justa, na 
medida em que o acesso seja universal e regulado pelo gestor. E solidária, na medida em que quem tem recursos pode também estar contribuindo para que outros que fazem uso exclusivamente do SUS tenham melhores condições assistenciais do que não essas as quais nós vimos no início dessa audiência.

Por fim afirma-se: "nós entendemos que não se pode abrir mão do acesso universal e igualitário sobre regulação do gestor".

Não existe na nossa legislação a proibição expressa da diferença de classe. Apesar disso é possível inferir da legislação brasileira que a diferença de classe não é uma possibilidade legal perante o nosso ordenamento jurídico, com base no exame constitucional e infraconstitucional, tendo como referência os princípios norteadores de nosso sistema constitucional de saúde.

A Constituição de 1988 afirma que a saúde é direito de todos e dever do Estado garantido mediante políticas que visem redução de riscos e acesso universal e igualitário às ações e serviços de saúde (11). Somente com esse artigo a CF trouxe dois princípios que regem o SUS: universalidade e igualdade.

"Pelo princípio de universalidade, o indivíduo passa a ter direito ao acesso a todos os serviços públicos de saúde, bem como àqueles conveniados em todos os níveis de assistência, livre de privilégios ou preconceitos" (12).

É importante lembrar que antes do advento da constituição vigente o acesso a serviços de saúde era devido somente a trabalhadores formais. Os princípios da universalidade e da igualdade quebram com essa lógica, estendendo o direito à saúde a todos os brasileiros.

A legislação ordinária também traz dispositivos que estão na direção oposta da diferença de classe. A Lei nํ․ 8080/90, no Art. 7ํㅡ, apresenta o princípio da universalidade de acesso aos serviços e fala ainda da igualdade da assistência à saúde sem preconceitos ou privilégios de qualquer espécie. Entende-se que não é possível a adoção da diferença de classe nesse contexto que proíbe de forma clara a instituição de diferença, seja ela qual for, para o acesso ou atendimento.

O pagamento de diferença ou co-pagamento também não encontra respaldo nas leis. O artigo 48, da Lei nº. 8080, afirma: “a gratuidade das ações e serviços de saúde fica preservada nos serviços públicos contratados, ressalvando-se as cláusulas dos contratos 
ou convênios estabelecidos com as entidades privadas" (13). Ou seja, no sistema público de saúde não pode ser cobrada nenhuma taxa pela prestação do serviço.

Outro dispositivo em que a gratuidade está expressamente garantida é no artigo 2ํㅡ, inciso I, da Lei Complementar №. 141, que dispõe sobre os valores mínimos que cada esfera de governo deve aplicar anualmente na saúde, onde se considera despesas em saúde aquelas que, entre outros aspectos: "sejam destinadas às ações e serviços públicos de saúde de acesso universal, igualitário e gratuito" (14).

Portanto, a universalidade no acesso aos serviços de saúde, a igualdade na sua prestação e a gratuidade dessas ações inviabiliza quaisquer medidas instituidoras de diferenças e privilégios no sistema público de saúde, tais como a diferença de classe.

\section{d) A autonomia do médico é fundamental no exercício da profissão.}

Em meio a esse debate, coloca-se a autonomia do médico como um princípio importante: "a autonomia do médico é basilar na relação médico/paciente, fundamento da medicina desde Hipócrates". A autonomia do médico se relaciona com a autonomia do paciente, e as duas convergem para uma relação de confiança que deve existir entre os dois. Além disso, contribui para que o paciente tenha mais segurança no tratamento ao qual vai se submeter.

Um dos pontos que fazem parte da diferença de classe é a escolha do médico de sua confiança, como afirma o sujeito do discurso: "direito de o paciente escolher o médico de sua confiança para ser hospitalizado. Isto é um dogma que vem desde o tempo de Hipócrates, e o sistema pretende acabar".

Acredita-se então, que a proibição da diferença de classe ameaça essa autonomia, já que no SUS o usuário, a partir do momento que dá entrada no sistema é paciente da instituição, e não de um médico de forma específica.

Aqui, nos deparamos com uma situação de conflito entre a autonomia do médico, quesito essencial para o bom exercício de sua profissão, e o seu exercício profissional dentro do sistema público de saúde:

A liberdade de atuação médica tem criado situações de conflito tanto em relação ao sistema público quanto ao sistema privado de saúde, nos quais este profissional encontra-se inserido como membro de uma equipe de saúde, e de um amplo corpo de servidores e funcionários. (15) 
Logo, dentro do serviço público não é possível considerar a liberdade do profissional médico e sua autonomia no exercício da profissão de forma dissociada do contexto no qual ele se insere: um sistema de saúde que preconiza o atendimento universal e integral. Assim ratifica Marques (15):

Estando hoje o médico inserido no mercado de trabalho como profissional assalariado e, inclusive, como servidor público ele está também inserido em um corpo social maior, composto de diversos princípios, diretrizes e regulamentações que configuram hoje a nossa política de Estado na área da saúde.

A diferença de classe propõe que o paciente seja atendido por médico de sua preferência e confiança, e isso é legítimo. Porém, é preciso ponderar esse aspecto com outros que integram o SUS, principalmente, considerando que este possui uma dinâmica própria de oferta de serviços. Sendo um sistema que atende demandas de tantas pessoas com necessidades tão distintas, é difícil permitir que cada paciente escolha o profissional que vai atendê-lo, justamente pela lógica de organização dos sistemas de base universal, como o SUS.

Portanto, sob o ponto de vista político, há que se ponderar a escolha individual do médico em relação às políticas de saúde, e a forma como essa política é estruturada, inclusive em relação à lista de procedimentos e medicamentos oferecidos pelo sistema, que deve ordenar a prescrição do profissional médico dentro do SUS, de forma a racionalizar a prestação coletiva.

\section{Considerações finais}

Para quem não conhece a trajetória das lutas pela criação do SUS e pela democratização na área da saúde, a diferença de classe pode parecer só mais uma forma de ser atendido no SUS, uma ideia despretensiosa. Mas é preciso analisar essa questão de forma menos superficial.

Estamos falando de uma proposta que busca estabelecer diferenças no atendimento dado pelo SUS com base em critérios de renda ou poder aquisitivo. O estabelecimento de qualquer diferença por si só já fere o texto constitucional que afirma em seu artigo 196 que o Estado brasileiro deve garantir o acesso à saúde de forma universal e igualitária (11) . 
Essa diferença poderia ser feita com base no pagamento ou não de um valor determinado para se ter melhores condições de hotelaria. A Lei nํ. 8080/90 traz como um de seus princípios a igualdade da assistência à saúde, sem preconceitos ou privilégios de qualquer espécie (13).

O SUS é uma política de saúde, e tem como um dos seus objetivos a redução das desigualdades entre os homens. Também é considerado uma política de proteção social inserido na seguridade social - que tem por finalidade proteger o cidadão contra riscos socioeconômicos que podem colocá-lo em condições vulneráveis (16). Novamente, a diferença de classe se mostra incompatível com o sistema.

Para além das questões normativas e estruturais que dizem respeito ao SUS é preciso pensar no impacto da diferença de classe no âmbito social. É preciso pensar que as políticas de saúde não interferem somente nas questões desse meio. Uma mudança no sistema de saúde como foi proposta pelo CREMERS teria sim impactos sociais.

Fleury e Ouverney (16) sintetizam esse pensamento:

A implantação de determinada política de saúde envolve a difusão de informações sobre a natureza biológica das pessoas, de valores que vão guiar as relações sociais, de comportamento, e hábitos culturais, de referenciais de organização política, dentre outros elementos. Essas mensagens que estão implícitas ou explicitas nas políticas de saúde são referenciais que têm um forte poder sobre a ação das pessoas na construção de suas relações sociais na família, no emprego, nos espaços coletivos, além de influenciar a forma como as pessoas se percebem.

Nesse ponto, fica claro que as políticas interferem na formação de referenciais éticos, legitimando concepções e valores junto à sociedade, contribuindo para a redefinição de padrões culturais, produzindo impactos reais na estrutura social.

Mas o STF, em novembro de 2015, decidiu pela improcedente do pedido da instituição dessa modalidade no SUS, reforçando seu caráter público.

Nessa reflexão, é preciso considerar que o SUS busca não somente ser um sistema eficiente que traduza na prática seus princípios instituidores, mas um mecanismo de construção de uma sociedade mais justa e solidária, como está na Constituição de 1988. A diferença de classe não passou e jamais passará pois somente fere apenas a legislação brasileira, mas representa também um retrocesso no que tange aos direitos sociais. 


\section{Referências}

1 - Brasil. Regimento Interno: atualizado até junho de 2014 - consolidado e atualizado até maio de 2002 por Eugênia Vitória Ribas. STF. Brasília [Acesso em 1 out 2014] Disponível em

http://www.stf.jus.br/arquivo/cms/legislacaoRegimentolnterno/anexo/RISTF Junho $2014 \mathrm{v}$ ersao eletronica.pdf

2 - Caregnato RCA, Mutti R. Pesquisa qualitativa: análise de discurso versus análise de conteúdo. Texto Contexto Enferm. 2006 [Acesso em 15 set 2014], 15(4):679-84. Disponível em http://www.scielo.br/scielo.php?script=sci arttext\&pid=S0104-07072006000400017

3 - Turato ER. Métodos qualitativos e quantitativos na área da saúde: definições, diferenças e seus objetos de pesquisa. Rev. Saúde Pública. 2005 [Acesso em 15 set 2014], 39(3):507-14 (509). Disponível em http://www.scielo.br/scielo.php?pid=S0034$89102005000300025 \&$ script=sci arttext

4 - Gerhardt TE, Silveira DT. Métodos de pesquisa. Porto Alegre: UFRGS; 2009. [Acesso em 19 out 2014]. Disponível em http://www.ufrgs.br/cursopgdr/downloadsSerie/derad005.pdf

5- Lefevre F, Lefevre AMC. O Discurso do Sujeito Coletivo: um novo enfoque em pesquisa qualitativa (desdobramentos). Caxias do Sul: EDUCS; 2003

6 - Escorel S. Os dilemas da equidade em saúde: aspectos conceituais. Organização PanAmericana da Saúde. 2001 [Acesso em 29 out 2014]. Disponível em http://biblioteca.planejamento.gov.br/biblioteca-tematica-1/textos/saude-epidemiasxcampanhas-dados-descobertas/texto-83-2013-os-dilemas-da-equidade-em-saudeaspectos-conceituais.pdf

7 - Whitehead M. The concepts and principles of equity in health. International Journal of Health Service. 1992 [Acesso em 1 nov 2014], 22(3):429-445. Disponível em http://publicaciones.ops.org.ar/publicaciones/piezas\%20comunicacionales/cursoDDS/curso eng/Textos\%20Completos/the\%20concepts\%20and\%20principles\%20of\%20equity\%20and \%20health.pdf

8 - Vianna SM, et al. Medindo as desigualdades em saúde no Brasil: uma proposta de monitoramento. Organização Pan-Americana da Saúde e Instituto de Pesquisa Econômica Aplicada. 2001 [Acesso em 1 nov. 2014]. Disponível em http://www.eadadm.ufsc.br/ ftpcursos/saude/2008/biblioteca/outraspublicacoes/desigual.pd $\underline{f}$

9 - Travassos C, De Castro MSM. Determinantes e desigualdades sociais no acesso e na utilização de serviços de saúde. In: Giovanella L et al, Políticas e Sistemas de Saúde no Brasil. Rio de Janeiro: FIOCRUZ; 2012, 1100 p. 
10 - Brasil. Relatório Final da Comissão Nacional sobre os Determinantes Sociais da Saúde: as causas sociais das iniquidades em saúde no Brasil. CNDSS. Brasil, 2008. [Acesso em 3 out 2014]. Disponível em http://bvsdss.icict.fiocruz.br/home/bvsdss/bvs/htdocs//local/File/relatorio cndss.pdf

11 - Brasil. Constituição da República Federativa do Brasil. Brasília, 5 out 1988. [Acesso em 25 out. 2014]. Disponível em

http://www.planalto.gov.br/ccivil 03/Constituicao/Constituicao.htm

12 - Pontes APM et al . O princípio de universalidade do acesso aos serviços de saúde: 0 que pensam os usuários. Esc. Anna Nery. 2009 [Acesso em 29 out 2014], 13(3):500-07. Disponível em http://www.scielo.br/scielo.php?script=sci arttext\&pid=S141481452009000300007\&lng=pt\& $\underline{\text { nrm=iso }}$

13 - Brasil. Lei oㅛ 8.080, de 19 de setembro de 1990. Dispõe sobre as condições para a promoção, proteção e recuperação da saúde, a organização e o funcionamento dos serviços correspondentes e dá outras providências. Brasília. [Acesso em 15 set 2014]. Disponível em http://www.planalto.gov.br/ccivil 03/Leis/L8080.htm

14 - Brasil. Lei complementar no 141, de 13 de janeiro de 2012. Regulamenta o $\S 30$ do art. 198 da Constituição Federal para dispor sobre os valores mínimos a serem aplicados anualmente pela União, Estados, Distrito Federal e Municípios em ações e serviços públicos de saúde; estabelece os critérios de rateio dos recursos de transferências para a saúde e as normas de fiscalização, avaliação e controle das despesas com saúde nas três esferas de governo. Brasília. [Acesso em 15 set 2014]. Disponível em http://www.planalto.gov.br/CCIVIL 03/LEIS/LCP/LCp141.htm

15 - Marques SB. O direito ao acesso universal a medicamentos no Brasil: diálogo entre $o$ direito, a política e a técnica médica [Tese] São Paulo: Faculdade de Saúde Pública, Universidade de São Paulo; 2011.

16 - Fleury S, Ouverney SM. Política de Saúde: Uma política social. In: Giovanella L et al. Políticas e Sistemas de Saúde no Brasil. Rio de Janeiro: Fiocruz; 2012. 1100 p. 